\title{
Atributos físicos do solo, adubado com lodo de esgoto e silicato de cálcio e magnésio
}

\author{
Marck Morais Maiol, Regynaldo Arruda Sampaio², Altina Lacerda Nascimento*3, \\ Fabiano Barbosa de Souza Prates ${ }^{4}$, Marcio Neves Rodrigues ${ }^{5}$, Humberto Pereira da Silva ${ }^{6}$, Adélio Nunes Dias ${ }^{7}$, \\ Claúdio Eduardo Silva Freitas ${ }^{7}$
}

\section{RESUMO}

Este trabalho teve como objetivo avaliar o efeito da aplicação de lodo de esgoto e de silicato de cálcio e magnésio sobre os atributos físicos de um Cambissolo Háplico, cultivado com girassol. Os tratamentos foram distribuídos em

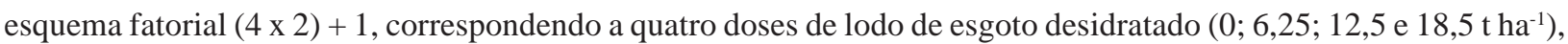
duas doses de silicato de cálcio e magnésio $\left(0\right.$ e $\left.240 \mathrm{~g} \mathrm{~m}^{-1}\right)$ e um tratamento adicional com adubação mineral. $\mathrm{O}$ delineamento utilizado foi em blocos casualizados, com três repetições. Após 150 dias da adubação, coletaram-se amostras de solos, nas camadas de 0-20 e 20-40 cm, para avaliação da densidade aparente, densidade de partícula, porosidade total, grau de dispersão, grau de floculação, índice de estabilidade de agregados, diâmetro médio ponderado, diâmetro médio geométrico e resistência do solo à penetração. O tratamento adicional, correspondente à adubação mineral, não diferiu dos tratamentos correspondentes às adubações com lodo de esgoto e silicato de cálcio e magnésio, em relação aos atributos físicos do solo. Para o silicato de cálcio e magnésio, também não se constataram diferenças nos atributos físicos do solo, entre a dose zero e $240 \mathrm{~g} \mathrm{~m}^{-1}$. Por outro lado, a aplicação de lodo de esgoto diminuiu o grau de dispersão de argila e aumentou a porosidade total do solo, o grau de floculação de argilas e o índice de estabilidade de agregados a úmido, não tendo, porém, influenciado os demais atributos físicos.

Palavras-chave: biossólido, matéria orgânica, densidade do solo, estabilidade de agregados.

\section{ABSTRACT}

\section{Physical attributes of soil fertilized with sewage sludge and with calcium and magnesium silicates}

This study aimed to evaluate the effect of sewage sludge and calcium and magnesium silicate on the physical attributes of a Cambisol cultivated with sunflower. The treatments were arranged in a factorial $(4 \times 2)+1$, corresponding to four doses of sewage sludge $\left(0,6.25,12.5\right.$ and $18.5 \mathrm{t} \mathrm{ha}^{-1}$, in dry basis $)$, two doses of calcium and magnesium silicate $\left(0\right.$ and $\left.240 \mathrm{~g} \mathrm{~m}^{-1}\right)$ and an additional treatment with chemical fertilizers. The experimental design was randomized blocks with three replications. After 150 days of fertilization, were collected soil samples at depth of 0-20 and 20-40 cm for the evaluation of bulk density, particle density, total porosity, water dispersible clay, flocculation index, aggregate stability index, mean weight diameter, geometric mean diameter and soil penetration resistance. The additional treatment,

\footnotetext{
Received 03/12/2010 and accepted for publication 06/09/2011

' Engenheiro- Agrônomo. Instituto Ciências Agrárias/UFMG. Av. Universitária, nº1000, Bairro Universitário, 39404-006, Montes Claros-MG. marckmaio.agrogeo@bol.com.br ${ }^{2}$ Engenheiro- Agrônomo. Doutor. Instituto Ciências Agrárias/UFMG, Av. Universitária, nº 1000, Bairro Universitário, 39404-006, Montes Claros-MG. rsampaio@ufmg.br ${ }^{3}$ Engenheira Agrônoma. Instituto Ciências Agrárias/UFMG, Av, Universitária, nº1000, Bairro Universitário, 39404- 006, Montes Claros-MG. altinalacerda@ yahoo.com.br (*Autor correspondente)

${ }^{4}$ Engenheiro- Agrônomo,Doutorando. Departamento de Solos, Instituto de Agronomia, Universidade Federal Rural do Rio de Janeiro, Rodovia BR 465, Km 7, 23890-000, Seropédica-RJ. fbprates@gmail.com

${ }^{5}$ Biólogo. Instituto Ciências Agrárias/UFMG, Av, Universitária, nº1000, Bairro Universitário, 39404-006, Montes Claros-MG. marcionrodrigues@gmail.com

${ }^{6}$ Engenheiro- Agrônomo, Mestrando em Fitotecnia. Departamento Agricultura/UFLA, Universidade Federal de Lavras, 37200-000, Lavras-MG. hurnbertofu@ yahoo.com.br ${ }^{7}$ Graduando em Zootecnia. Instituto Ciências Agrárias/UFMG. Av. Universitária, nº1000, Bairro Universitário, 39404. 006, Montes Claros-MG. freitasmoc@ hotmail.com; adelionunes7@yahoo.com.br
} 
corresponding to chemical fertilizer, did not differ from the corresponding treatments with sewage sludge fertilizer and calcium and magnesium silicate in relation to soil physical attributes. For calcium and magnesium silicate, also were not found differences in soil physical characteristics between dose zero and $240 \mathrm{~g} \mathrm{~m}^{-1}$. On the other hand, the application of sewage sludge to soil decreased the water dispersible clay and increased the soil total porosity, the clay flocculation index and wet aggregate stability index. There was no influence of sewage sludge on the other attributes physical of soil.

Key words: Biosolids, organic matter, soil bulk density, aggregate stability.

\section{INTRODUÇÃO}

A utilização na agricultura do lodo de esgoto e de escórias de siderurgia, como os silicatos de cálcio e magnésio, tem sido objeto de crescente interesse, não só por causa do alto custo e dos impactos ambientais decorrentes de outras alternativas de descarte, como pela necessidade de disposição de quantidades cada vez maiores desses resíduos, provenientes do tratamento de esgotos urbanos e dos fornos de siderurgia. Além disso, em razão dos elevados teores de matéria orgânica do lodo de esgoto e dos altos teores de cátions floculantes dos silicatos, contribui para a melhoria das condições físicas e químicas do solo, com forte impacto positivo sobre a conservação dos solos.

Às vantagens agronômicas da aplicação desses resíduos nas lavouras, somam-se dois importantes aspectos da sustentabilidade ambiental, o primeiro representado pela reciclagem de nutrientes e da energia (matéria orgânica) nele contido e, o segundo, pela contribuição dessa reciclagem para a preservação das jazidas que fornecem os minérios utilizados na fabricação dos adubos comerciais (Dynia et al., 2006).

Com relação aos atributos físicos, a aplicação de lodo de esgoto proporciona aumento na porosidade total, macroporosidade e retenção de água do solo (Aggelides \& Londra, 2000; Debosz et al., 2002; Corrêa et al., 2009; Maria et al., 2010) e diminuição na densidade do solo (Aggelides \& Londra, 2000; Trannin et al., 2008; Maria et al., 2010). Jorge et al. (1991), estudando a adição de 10,0 t ha $^{-1}$ ano $^{-1}$ de lodo de esgoto, em Latossolo Vermelho argiloso, verificaram alterações na relação entre macro e microporos, sem, no entanto, constatar alterações significativas na porosidade total e densidade do solo.

Trannin et al. (2008) verificaram que mesmo a menor dose de lodo de esgoto ( $\left.6 \mathrm{t} \mathrm{ha}^{-1}\right)$, aplicada por dois anos consecutivos, promoveu alterações significativas no sentido de melhoria dos atributos físicos de um Cambissolo distrófico. No entanto, Camilotte et al. (2006) não verificaram alterações nos atributos físicos de um Latossolo Vermelho distroférrico argiloso. Segundo Marciano et al. (2001), quando o solo originalmente possui uma boa es- trutura, podem não ocorrer melhorias nos atributos físicos, mesmo com a aplicação de grandes quantidades de lodo de esgoto.

Conforme Epstein (1999), o silício é o segundo elemento mais abundante da crosta terrestre e se acumula nos tecidos de todas as plantas, representando de 0,1 a $10 \%$ de sua matéria seca. Korndörfer et al. (2002) relatam que a aplicação de silício corrige a acidez do solo, aumenta a disponibilidade de fósforo, a saturação por bases e os teores de cálcio e magnésio do solo, além de proporcionar benefícios às plantas, tais como, maior resistência da parede celular, maior taxa fotossintética, menor perda de água, maior absorção de cálcio e magnésio e aumento da produtividade.

Como resultado dos efeitos positivos que provoca no solo, o silicato de cálcio e magnésio, pela sua riqueza em cátions floculantes, aumenta o grau de floculação do solo, melhorando as suas condições físicas (Alleoni et al., 2009). Os silicatos também melhoram o desenvolvimento das plantas, o que indiretamente influencia as condições físicas do solo, uma vez que, segundo Silva \& Mendonça (2007), as raízes vivas de plantas crescendo no solo também contribuem para formar macroagregados, por meio da pressão mecânica que contribui para aproximar as partículas de solo, além da produção de exsudados com capacidade cimentante. Os exsudados podem servir de substrato para micro-organismos, estimulando sua atividade, levando à produção de novos agentes cimentantes.

Diante do exposto, este trabalho teve como objetivo avaliar o efeito da aplicação de lodo de esgoto e de silicato de cálcio e magnésio como condicionadores dos atributos físicos do solo.

\section{MATERIAL E MÉTODOS}

O experimento foi desenvolvido no período de abril a setembro de 2008, em Cambissolo Háplico, no Instituto de Ciências Agrárias (ICA) da Universidade Federal de Minas Gerais (UFMG), em Montes Claros - MG, latitude $16^{\circ} 51^{\prime} 38^{\prime \prime} \mathrm{S}$, longitude 44 $55^{\prime} 00^{\prime \prime} \mathrm{W}$ e altitude de $630 \mathrm{~m}$. O solo apresentou os seguintes atributos químicos e físicos: 3,71 dag $\mathrm{kg}^{-1}$ de matéria orgânica; 8,00 dag $\mathrm{kg}^{-1}$ de 
areia grossa; $28,00 \mathrm{dag} \mathrm{kg}^{-1}$ de areia fina; $36,00 \mathrm{dag} \mathrm{kg}^{-1} \mathrm{de}$ silte e $28,00 \mathrm{dag} \mathrm{kg}^{-1}$ de argila.

O experimento foi instalado no delineamento em blocos casualizados, com três repetições. Os tratamentos foram distribuídos em esquema fatorial $4 \times 2+1$, sendo 4 doses de lodo de esgoto desidratado $(0 ; 6,25 ; 12,5$ e 18,5 $\left.\mathrm{t} \mathrm{ha}^{-1}\right), 2$ doses de silicato de cálcio e magnésio $(0$ e $240 \mathrm{~g}$ $\mathrm{m}^{-1}$ ) e 1 tratamento adicional, composto pela adubação química para a cultura do girassol $\left(18,7 \mathrm{~g} \mathrm{~m}^{-1}\right.$ de formulado 4-30-10), conforme a recomendação da $5^{\mathrm{a}}$ Aproximação para uso de corretivos e fertilizantes em Minas Gerais (CFSEMG, 1999).

O lodo de esgoto desidratado foi coletado na Estação de Tratamento de Esgoto - ETE, da Copasa, no município de Juramento - MG, tendo as seguintes características químicas: $\mathrm{pH}$ em água $=4,4 ; \mathrm{C} . \mathrm{O}=62,4 \mathrm{~g} \mathrm{~kg}^{-1} ; \mathrm{P}$ Mehlich$1=2,8 \mathrm{~g} \mathrm{~kg}^{-1} ; \mathrm{K}=5,6 \mathrm{~g} \mathrm{~kg}^{-1} ; \mathrm{Ca}=5,5 \mathrm{~g} \mathrm{~kg}^{-1} ; \mathrm{Mg}=1,9 \mathrm{~g} \mathrm{~kg}^{-}$ ${ }^{1} ; \mathrm{S}=10,6 \mathrm{~g} \mathrm{~kg}^{-1} ; \mathrm{Zn}=24 \mathrm{mg} \mathrm{kg}^{-1} ; \mathrm{Fe} 34,5 \mathrm{mg} \mathrm{kg}^{-1} ; \mathrm{Mn}=$ $160 \mathrm{mg} \mathrm{kg}^{-1} ; \mathrm{Cu}=64 \mathrm{mg} \mathrm{kg}^{-1} ; \mathrm{Pb}=5,16 \mathrm{mg} \mathrm{kg}^{-1} ; \mathrm{Ni}=10,84$ $\mathrm{mg} \mathrm{kg}^{-1}$, extrator Mehlich-1; o silicato de cálcio e magnésio, contendo $36 \%$ de $\mathrm{CaO}, 9 \%$ de $\mathrm{MgO}$ e $10 \% \mathrm{Si}$, foi adquirido comercialmente.

O cálculo das variações das dosagens de lodo de esgoto baseou-se na quantidade de nitrogênio contida e na exigência da cultura do girassol quanto a este elemento, recomendada pela $5^{\text {a }}$ aproximação $\left(60 \mathrm{~kg} \mathrm{ha}^{-1} \mathrm{de} \mathrm{N}\right)$; também, na umidade do lodo, e na taxa de mineralização da matéria orgânica, estimada em 50\% ao ano. Para o silicato, calculou-se a dosagem de forma a fornecer $300 \mathrm{~kg} \mathrm{ha}^{-1} \mathrm{de}$ Si para o girassol, quantidade intermediária àquela recomendada por Faria (2000) para a cultura do arroz.

As parcelas experimentais foram constituídas de quatro linhas de semeadura, de 3,0 m de comprimento, com espaçamento entre linhas de $0,80 \mathrm{~m}$ a $0,2 \mathrm{~m}$ entre plantas. Adotaram-se, como área útil, duas linhas centrais de cada parcela experimental, desprezando-se $0,50 \mathrm{~m}$ de cada extremidade.

Aos 150 dias após a realização da adubação, foram coletadas amostras de solo, nas camadas de 0-20 e 20-40 cm para, de acordo com metodologia da EMBRAPA (1997), determinar a densidade aparente, a densidade de partícula, a porosidade total, o grau de dispersão e o grau de floculação. O índice de estabilidade dos agregados (IEA) foi calculado pela seguinte equação: IEA $(\%)=[$ (peso dos agregados - fração $<0,25 \mathrm{~mm}) /$ peso total da amostra]x 100. A resistência do solo à penetração foi determinada nas camadas de 0-5, 6-10, 11-15, 16-20, 21-25, 26-30, 31-35 e 36-40 cm de profundidade, utilizando-se o penetrômetro de impacto modelo IAA/Planalsucar - Stolf.

Os dados obtidos foram submetidos à análise de variância, sendo esta desdobrada em contrastes ortogonais, para comparar o tratamento adicional (adubação química) com os demais tratamentos aplicados. Para a compa- ração das médias referentes às doses de silicato de cálcio e magnésio, aplicou-se o teste de Tukey, até 5\% de probabilidade, enquanto, para as doses de composto de lodo de esgoto, ajustaram-se modelos de regressão, testando-se os coeficientes até $10 \%$ de probabilidade pelo teste t.

\section{RESULTADOS E DISCUSSÃO}

Na tabela 1, observa-se que não houve diferença nos atributos físicos do solo, quando a adubação foi feita com NPK ou com lodo de esgoto e silicato de cálcio e magnésio, exceto para o diâmetro médio ponderado seco e o diâmetro médio geométrico seco. Também, quanto à resistência do solo à penetração (Tabela 2), não foram constatadas diferenças entre a adubação com NPK e com lodo de esgoto e silicato de cálcio e magnésio.

Considerando-se que o lodo de esgoto é um resíduo rico em matéria orgânica e que esta exerce grande influência nos atributos físicos do solo (Bayer \& Mielniczuk, 2008), os resultados obtidos indicam que, provavelmente, a quantidade de matéria orgânica aplicada via lodo de esgoto não foi suficiente para promover mudanças nesses atributos, em relação à adubação mineral, principalmente considerando-se uma única aplicação do resíduo ao solo e as condições tropicais, cujas altas temperaturas favorecem o desenvolvimento de micro-organismos decompositores, com consequente aceleração da degradação da matéria orgânica, favorecida, ainda, pelo constante fornecimento de água à cultura. Nessas condições, levando-se em conta que o lodo de esgoto é rico em matéria orgânica facilmente mineralizável, pouco resíduo recalcitrante deve permanecer no solo, só influenciando os atributos físicos em aplicações sistemáticas e em prazos mais longos. Isto fica evidenciado em Melo (2002) que, após três anos de aplicação de dosagens superiores a 25 $\mathrm{t} \mathrm{ha}^{-1}$ de lodo de esgoto, na camada de $0-10 \mathrm{~cm}$, em dois Latossolos Vermelhos, um de textura média e outro de textura argilosa, não verificou aumento no teor de matéria orgânica do solo, só sendo apontado aumento, por Melo et al. (2004), no quinto ano do experimento.

A análise de variância revelou que não houve efeito significativo da interação dose de silicato de cálcio e magnésio $x$ dose de lodo de esgoto $(\mathrm{p} \geq 0,05)$. Comparando-se somente o efeito das doses de silicato de cálcio e magnésio (Tabelas 3 e 4), verificou-se que não houve nenhuma influência desse resíduo sobre os atributos físicos do solo, apesar de ele conter cálcio e magnésio, os quais podem influenciar a floculação de argilas e a agregação do solo (Correa et al., 2009). A falta de efeito do silicato de cálcio e magnésio sobre os atributos físicos do solo pode ser atribuída à baixa solubilização desse resíduo, uma vez que a água de irrigação utilizada era de origem calcária, com pH acima de 7,5. 
Tabela 1 - Contrastes ortogonais ${ }^{1}$ comparando a adubação mineral com adubação com lodo + silicato em relação aos diferentes atributos do solo

\begin{tabular}{|c|c|c|}
\hline \multirow{2}{*}{ Variável } & \multicolumn{2}{|c|}{ Profundidade } \\
\hline & $0-20 \mathrm{~cm}$ & $20-40 \mathrm{~cm}$ \\
\hline Densidade Aparente $\left(\mathrm{g} \mathrm{cm}^{-3}\right)$ & $2,14-2,26=-0,12 \mathrm{~ns}$ & $2,25-2,28=-0,03 \mathrm{~ns}$ \\
\hline Densidade de Partículas $\left(\mathrm{g} \mathrm{cm}^{-3}\right)$ & $2,44-2,45=-0,01 \mathrm{~ns}$ & $2,41-2,43=-0,02 \mathrm{~ns}$ \\
\hline Porosidade Total (\%) & $12,24-7,53=4,71 \mathrm{~ns}$ & $6,72-6,20=0,52 \mathrm{~ns}$ \\
\hline Grau de dispersão (\%) & $27,66-34,44=-6,78 \mathrm{~ns}$ & $34,40-42,69=-8,29 n s$ \\
\hline Grau de Floculação (\%) & $72,34-65,56=6,78 \mathrm{~ns}$ & $65,66-57,31=8,35 \mathrm{~ns}$ \\
\hline Diâmetro Médio Ponderado Seco (mm) & $4,50-4,50=0,00 \mathrm{~ns}$ & $4,48-4,50=-0,02 * *$ \\
\hline Diâmetro Médio Geométrico Seco (mm) & $0,85-0,87=-0,02 \mathrm{~ns}$ & $0,89-0,87=0,02 *$ \\
\hline Índice de Estabilidade de Agregados Seco (\%) & $99,96-99,94=0,02 \mathrm{~ns}$ & $99,93-99,94=-0,01 \mathrm{~ns}$ \\
\hline Diâmetro Médio Ponderado Úmido (mm) & $1,84-2,78=-0,94 \mathrm{~ns}$ & $2,62-2,73=-0,11 \mathrm{~ns}$ \\
\hline Diâmetro Médio Geométrico Úmido (mm) & $1,12-1,08=0,04 \mathrm{~ns}$ & $1,07-1,08=-0,01 \mathrm{~ns}$ \\
\hline Índice de Estabilidade de Agregados Úmido (\%) & $72,49-84,64=-12,15 \mathrm{~ns}$ & $78,22-81,45=-3,23 n s$ \\
\hline
\end{tabular}

${ }^{1}$ Contraste ortogonal (Adubação mineral vs Adubação com lodo + silicato).

$\mathrm{ns}, *$, **, não significativo e significativos a 5 e $1 \%$ de probabilidade, respectivamente, pelo teste $\mathrm{F}$.

As densidades, aparente e de partículas, não foram sensíveis às mudanças ocorridas no solo com a aplicação do lodo de esgoto (Tabela 5). Jorge et al. (1991), Andrade et al. (2005) e Camilotti et al. (2006) afirmam que aplicações de lodo de esgoto não influenciam a densidade do solo, porém, Aggelides \& Londra (2000); Trannin et al. (2008) e Maria et al. (2010) verificaram redução da densidade aparente do solo com a aplicação de lodo de esgoto. Melo et al. (2004) aplicaram doses crescentes de lodo de esgoto, distribuídas ao longo de cinco anos, em dois tipos de solo (Latossolo Vermelho distrófico e Latossolo Vermelho eutroférrico) e observaram redução significativa da densidade aparente do solo, com a aplicação de 50 $\mathrm{t} \mathrm{ha}^{-1}$, apenas no Latossolo Vermelho distrófico. Dessa forma, os resultados para a densidade do solo relacionam-se não somente com a dose do resíduo, mas também com o tipo de solo que o recebe, ficando evidente que só em períodos mais longos de aplicação é que o lodo de esgoto influencia os atributos físicos do solo.

De acordo com Bayer e Mielniczuk (2008), a matéria orgânica diminui a densidade do solo, como consequência da melhoria na agregação das partículas. García-Orenes et al. (2005) observaram redução da densidade do solo pela aplicação de lodo de esgoto, mas essa redução foi negativamente correlacionada com o carbono orgânico do solo. De acordo com esses autores, a diminuição da densidade do solo foi, provavelmente, devida não só ao efeito de diluição da adição de matéria orgânica, menos densa, à matéria mineral, mais densa, mas, principalmente, à agregação das partículas do solo.

A porosidade total do solo estudado (Tabela 5) apresenta valores menores do que aqueles encontrados por Portugal et al. (2008), em Cambissolo Háplico, submetido a diferentes formas de manejos e cujos valores variaram de $44,6 \%$, para pastagem, até 59,4, para matas, na camada de 0-20 cm, e por Lima et al. (2006), que, ao estudarem a variabilidade espacial de características físico-hídricas de um Cambissolo Háplico, encontraram valores de porosidade total que variaram de 50,25 a 54,33\%, também na camada de 0 a $20 \mathrm{~cm}$. Os resultados sugerem que o solo deste trabalho, com um histórico de uso e manejo de pastagem com bovinos e diversos plantios sucessivos, encontra-se numa condição de extrema compactação. Assim, as dosagens de lodo de esgoto utilizadas promoveram aumento na porosidade total do solo na camada de 0 $20 \mathrm{~cm}$, porém, a quantidade máxima de matéria orgânica adicionada e o curto tempo de sua aplicação foram insuficientes para provocar maiores modificações nos atributos físicos do solo, uma vez que o valor máximo atingido, com base na equação de regressão, foi de $10,18 \%$.

Aggelides \& Londra (2000) observaram que aumentos na taxa de aplicação de lodo de esgoto promoveram aumentos proporcionais na porosidade total, em duas classes de solos. Resultado semelhante também foi observado por Corrêa et al. (2009). Apesar de não verificarem

Tabela 2 - Contrastes ortogonais ${ }^{1}$, comparando a adubação mineral com adubação com lodo + silicato em relação à resistência à penetração $(\mathrm{MPa})$, em diferentes profundidades do solo

\begin{tabular}{lc}
\hline Profundidade do solo & Contraste ortogonal $^{1}$ \\
\hline $0-5 \mathrm{~cm}$ & $1,88-2,20=-0,32 \mathrm{~ns}$ \\
$6-10 \mathrm{~cm}$ & $5,09-5,86=-0,77 \mathrm{~ns}$ \\
$11-15 \mathrm{~cm}$ & $8,85-9,33=-0,48 \mathrm{~ns}$ \\
$16-20 \mathrm{~cm}$ & $9,41-10,03=-0,62 \mathrm{~ns}$ \\
$21-25 \mathrm{~cm}$ & $9,64-10,31=-0,67 \mathrm{~ns}$ \\
$26-30 \mathrm{~cm}$ & $10,96-11,17=-0,21 \mathrm{~ns}$ \\
$31-35 \mathrm{~cm}$ & $11,81-12,07=-0,26 \mathrm{~ns}$ \\
$36-40 \mathrm{~cm}$ & $11,76-12,80=-1,04 \mathrm{~ns}$ \\
\hline
\end{tabular}

${ }^{1}$ Contraste ortogonal (Adubação mineral vs Adubação com lodo + silicato).

$\mathrm{ns}=$ Não significativo. 
alterações na porosidade total do solo, Melo et al. (2004) verificaram aumento da macroporosidade do solo, na camada de 0-10 cm de profundidade, com aplicação de doses a partir de 47,5 t ha-1 de lodo de esgoto. Por outro lado, Camilotti et al. (2006) não constataram efeito da aplicação desse resíduo na macroporosidade, microporosidade e porosidade total de um Latossolo Vermelho distroférrico argiloso.

Em relação ao grau de dispersão (GD) e ao grau de floculação (GF) (Tabela 5), observa-se que a adição de doses crescentes de lodo de esgoto provocou redução do GD e aumento do GF do solo, principalmente na camada de 0 a $20 \mathrm{~cm}$. Fica evidente, portanto, que os elementos minerais solúveis, já existentes no lodo, somados àqueles oriundos da rápida mineralização da matéria orgânica, exerceram importante efeito floculante do solo, provavelmente pelo aumento da força iônica da solução e consequente contração da dupla camada difusa, conforme descrito em Ernani (2008), sendo que os solos mais novos, como os cambissolos, com maior CTC, são muito sensíveis às variações da concentração iônica da solução. Convém destacar que o desenvolvimento da estrutura do solo inicia-se com o fenômeno da floculação, porém, somente após a ação prolongada da matéria orgânica e de compostos do solo, é que adquire a estabilidade necessária (Bayer \& Mielniczuk, 2008). Entretanto, em Latossolo Vermelho e Latossolo Vermelho- Amarelo, os quais possuem naturalmente alto grau de floculação, Tavares Filho et al. (2010) não constataram diferenças significativas, quanto aos teores de argila dispersa em água, entre solos adubados com lodo de esgoto, em doses de até $48 \mathrm{t} \mathrm{ha}^{-1}$, e solos não adubados com o resíduo orgânico.

Dentre os índices de estabilidade de agregados, nas diferentes camadas do solo, observa-se que somente o índice de estabilidade de agregado em água, na camada de 0-20 cm (Tabela 5) foi sensível ao incremento de lodo de esgoto, atingindo valores mais elevados com as maiores aplicações desse resíduo. A influência no índice de estabilidade de agregados somente em água corrobora a afirmação anterior de que o efeito do lodo deu-se, principalmente, pela ação de seus eletrólitos, mantendo as argilas floculadas em água e preservando os agregados do solo. O índice de estabilidade de agregados a seco apresenta valor alto, indicando que esse solo apresenta boa resistência quanto aos processos de erosão eólica, entretanto, o menor índice de estabilidade de agregados em água, na ausência do lodo de esgoto, indica um pouco menos de resistência deste solo à erosão hídrica, o que é inerente à ordem Cambissolos. Isto destaca a importância das adições e manejo constantes de matéria nesses solos.

García-Orenes et al. (2005) verificaram que a aplicação de lodo de esgoto altera a agregação das partículas do solo, mas os resultados variam conforme o tipo de solo e a textura. Segundo Silva \& Mendonça (2007), em solos com mineralogia dominada por argila 2:1 a matéria orgânica é o principal agente estabilizante dos agregados. Entretanto, nos solos cuja fração argila é dominada

Tabela 3 - Atributos físicos do solo em função das doses de silicato aplicadas

\begin{tabular}{|c|c|c|c|c|c|c|c|c|c|c|c|}
\hline $\begin{array}{l}\text { DSi } \\
\left(\mathrm{g} \mathrm{m}^{-1}\right)\end{array}$ & $\begin{array}{c}\text { DS } \\
\left(\mathrm{g} \mathrm{cm}^{-3}\right)\end{array}$ & $\begin{array}{c}\text { DP } \\
\left(\mathrm{g} \mathrm{cm}^{-3}\right)\end{array}$ & $\begin{array}{l}\text { PT } \\
(\%)\end{array}$ & $\begin{array}{l}\text { GD } \\
(\%)\end{array}$ & $\begin{array}{l}\text { GF } \\
(\%)\end{array}$ & $\begin{array}{c}\text { DMPS } \\
(\mathbf{m m})\end{array}$ & $\begin{array}{c}\text { DMGS } \\
(\mathrm{mm})\end{array}$ & $\begin{array}{c}\text { IEAS } \\
(\%)\end{array}$ & $\begin{array}{c}\text { DMPU } \\
(\mathrm{mm})\end{array}$ & $\begin{array}{c}\text { DMGU } \\
(\mathrm{mm})\end{array}$ & $\begin{array}{c}\text { IEAU } \\
(\%)\end{array}$ \\
\hline \multicolumn{12}{|c|}{ Profundidade do solo de 0 a $20 \mathrm{~cm}$} \\
\hline 0,0 & $2,24 \mathrm{a}$ & $2,45 \mathrm{a}$ & $8,43 \mathrm{a}$ & $32,80 \mathrm{a}$ & $67,20 \mathrm{a}$ & $4,495 \mathrm{a}$ & $0,865 \mathrm{a}$ & $99,94 \mathrm{a}$ & $2,796 \mathrm{a}$ & $1,082 \mathrm{a}$ & $83,30 \mathrm{a}$ \\
\hline 240,0 & $2,29 \mathrm{a}$ & $2,45 \mathrm{a}$ & $6,63 \mathrm{a}$ & $36,09 \mathrm{a}$ & $63,91 \mathrm{a}$ & $4,495 \mathrm{a}$ & $0,864 \mathrm{a}$ & $99,95 \mathrm{a}$ & $2,762 \mathrm{a}$ & $1,087 \mathrm{a}$ & $85,99 \mathrm{a}$ \\
\hline \multicolumn{12}{|c|}{ Profundidade do solo de 20 a $40 \mathrm{~cm}$} \\
\hline 0,0 & $2,29 \mathrm{a}$ & $2,43 \mathrm{a}$ & $5,85 \mathrm{a}$ & $40,57 \mathrm{a}$ & $59,43 a$ & $4,495 \mathrm{a}$ & $0,865 \mathrm{a}$ & $99,930 \mathrm{a}$ & $2,517 \mathrm{a}$ & $1,094 \mathrm{a}$ & $81,246 \mathrm{a}$ \\
\hline 240,0 & $2,27 \mathrm{a}$ & $2,43 a$ & $6,55 \mathrm{a}$ & $40,65 \mathrm{a}$ & $59,35 \mathrm{a}$ & $4,495 \mathrm{a}$ & $0,866 \mathrm{a}$ & $99,942 \mathrm{a}$ & $2,936 \mathrm{a}$ & $1,067 \mathrm{a}$ & $81,661 \mathrm{a}$ \\
\hline
\end{tabular}

DSi = Dose de silicato de cálcio e magnésio; DS = Densidade Aparente; DP = Densidade de Partículas; PT = Porosidade Total; GD = Grau de Dispersão; GF = Grau de Floculação; DMPS = Diâmetro Médio Ponderado Seco; DMGS = Diâmetro Médio Geométrico Seco; IEAS = Índice de Estabilidade de Agregados Seco; DMPU = Diâmetro Médio Ponderado Úmido; DMPU = Diâmetro Médio Geométrico Úmido e IEAU = Índice de Estabilidade de Agregados Úmido.

Para cada variável, médias, seguidas da mesma letra na vertical, não diferem estatisticamente entre si, a 5\% de probabilidade, pelo teste t.

Tabela 4 - Resistência à penetração em diferentes camadas de um Cambissolo Háplico, em função da aplicação, ou não, de silicato de cálcio e magnésio

\begin{tabular}{lcccccccc}
\hline \multicolumn{7}{c}{ Resistência à penetração $(\mathbf{M P a})$} \\
\hline DSi $\left(\mathbf{g ~ m}^{-1}\right)$ & $\mathbf{0 - 5}(\mathbf{c m})$ & $\mathbf{6 - 1 0}(\mathbf{c m})$ & $\mathbf{1 1 - 1 5}(\mathbf{c m})$ & $\mathbf{1 6 - 2 0}(\mathbf{c m})$ & $\mathbf{2 1 - 2 5}(\mathbf{c m})$ & $\mathbf{2 6 - 3 0}(\mathbf{c m})$ & $\mathbf{3 1 - 3 5}(\mathbf{c m})$ & $\mathbf{3 6 - 4 0}(\mathbf{c m})$ \\
\hline 0,0 & $1,98 \mathrm{a}$ & $5,68 \mathrm{a}$ & $8,76 \mathrm{a}$ & $9,75 \mathrm{a}$ & $10,48 \mathrm{a}$ & $11,67 \mathrm{a}$ & $12,05 \mathrm{a}$ & $12,49 \mathrm{a}$ \\
240,0 & $2,43 \mathrm{a}$ & $6,04 \mathrm{a}$ & $9,90 \mathrm{a}$ & $10,32 \mathrm{a}$ & $10,14 \mathrm{a}$ & $10,68 \mathrm{a}$ & $12,10 \mathrm{a}$ & $13,13 \mathrm{a}$ \\
\hline
\end{tabular}

DSi = Dose de silicato de cálcio e magnésio.

Médias seguidas de mesma letra na vertical não diferem estatísticamente entre si, a 5\% de probabilidade, pelo teste t. 
por caulinita e oxi-hidróxidos de ferro e alumínio, em razão da forte ação cimentante das partículas primárias, o papel da matéria orgânica parece ser proporcionalmente menor.

Souza et al. (2005) constataram que a aplicação de 50 t ha ${ }^{-1}$ de lodo de esgoto, distribuído ao longo de cinco anos, aumentou a agregação do solo na camada em que foi incorporado o resíduo $(0-10 \mathrm{~cm})$. Esse resultado foi atribuído ao fato de a matéria orgânica apresentar grande superfície específica e capacidade de troca de cátions, possibilitando maior número de ligações eletrostáticas entre a matéria orgânica e as partículas do solo. Além disso, Bayer \& Mielniczuk (2008) relatam que inúmeros compostos, provenientes da decomposição da matéria orgânica por micro-organismos, são importantes na cimentação e na estabilização dos agregados.

Trannin et al. (2008) também verificaram aumento nos índices de estabilidade de agregados do solo, com o aumento da dose de lodo de esgoto. Segundo esses autores, além da adição da matéria orgânica, a aplicação de lodo de esgoto pode ter favorecido a estabilidade de agregados, pelo fornecimento de cátions polivalentes, essenciais para unir as frações orgânicas e de minerais de argila, sem os quais se dispersam.

O diâmetro médio ponderado e o diâmetro médio geométrico, determinados a seco e em água, nas diferentes camadas do solo, não foram influenciados pela aplicação de lodo de esgoto (Tabela 5), sendo os valores considerados altos (acima de $0,500 \mathrm{~mm}$ ), principalmente no método a seco, o que significa que, independentemente da aplicação do lodo, este solo tem uma boa estabilidade de agregados. Segundo Dufranc et al. (2004), o diâmetro médio ponderado é um índice que traduz a estabilidade dos agregados de toda a amostra, o que permite uma avaliação segura em relação a maior ou menor fragilidade do solo aos efeitos da erosão hídrica e eólica.

Ao contrário do observado neste experimento, Souza et al. (2005), avaliando o efeito da aplicação de doses crescentes de biossólidos no solo, constataram que o di-

Tabela 5 - Equações de regressão, relacionando os atributos físicos do solo com as doses de lodo aplicadas

\begin{tabular}{|c|c|c|c|}
\hline Propriedade & Unidade & Equação & $\mathbf{R}^{2}$ \\
\hline $\mathrm{DS}(0-20 \mathrm{~cm})$ & $\mathrm{g} \mathrm{cm}^{-3}$ & $\mathrm{Y}=\mathrm{Ym}=2,26$ & - \\
\hline DS $(20-40 \mathrm{~cm})$ & & $\mathrm{Y}=\mathrm{Ym}=2,28$ & \\
\hline $\mathrm{DP}(0-20 \mathrm{~cm})$ & & $\mathrm{Y}=\mathrm{Ym}=2,45$ & - \\
\hline DP $(20-40 \mathrm{~cm})$ & & $\mathrm{Y}=\mathrm{Ym}=2,42$ & \\
\hline PT $(0-20 \mathrm{~cm})$ & $\%$ & $Y=5,810956+0,012773^{\circ} X^{2}$ & 0,8653 \\
\hline PT $(20-40 \mathrm{~cm})$ & & $\mathrm{Y}=\mathrm{Ym}=6,20$ & - \\
\hline $\mathrm{GD}(0-20 \mathrm{~cm})$ & & $\mathrm{Y}=39,14-0,829176 * * * \mathrm{X}+0,022521 * * \mathrm{X}^{2}$ & 0,9933 \\
\hline $\mathrm{GD}(20-40 \mathrm{~cm})$ & & $\mathrm{Y}=\mathrm{Ym}=42,69$ & - \\
\hline $\mathrm{GF}(0-20 \mathrm{~cm})$ & & $Y=60,87+1,814664^{\circ} X^{0,5}$ & 0,9723 \\
\hline $\mathrm{GF}(20-40 \mathrm{~cm})$ & & $Y=51,38+2,218916 * X-0,109612 * X^{2}$ & 0,9840 \\
\hline IEAS $(0-20 \mathrm{~cm})$ & & $\mathrm{Y}=\mathrm{Ym}=99,943$ & - \\
\hline IEAS $(20-40 \mathrm{~cm})$ & & $\mathrm{Y}=\mathrm{Ym}=99,936$ & - \\
\hline IEAU $(0-20 \mathrm{~cm})$ & & $Y=78,14+2,516065^{\circ} \mathrm{X}$ & 0,7172 \\
\hline IEAU $(20-40 \mathrm{~cm})$ & & $\mathrm{Y}=\mathrm{Ym}=81,540$ & - \\
\hline DMPS $(0-20 \mathrm{~cm})$ & $\mathrm{mm}$ & $\mathrm{Y}=\mathrm{Ym}=4,495$ & - \\
\hline DMPS $(20-40 \mathrm{~cm})$ & & $\mathrm{Y}=\mathrm{Ym}=4,495$ & - \\
\hline DMPU $(0-20 \mathrm{~cm})$ & & $\mathrm{Y}=\mathrm{Ym}=2,779$ & - \\
\hline DMPU $(20-40 \mathrm{~cm})$ & & $\mathrm{Y}=\mathrm{Ym}=2,727$ & - \\
\hline DMGS $(0-20 \mathrm{~cm})$ & & $\mathrm{Y}=\mathrm{Ym}=0,865$ & - \\
\hline DMGS $(20-40 \mathrm{~cm})$ & & $\mathrm{Y}=\mathrm{Ym}=0,866$ & - \\
\hline DMGU $(0-20 \mathrm{~cm})$ & & $\mathrm{Y}=\mathrm{Ym}=1,084$ & - \\
\hline DMGU $(20-40 \mathrm{~cm})$ & & $\mathrm{Y}=\mathrm{Ym}=1,080$ & - \\
\hline $\mathrm{RP}(0-5 \mathrm{~cm})$ & $\mathrm{MPa}$ & $\mathrm{Y}=\mathrm{Ym}=2,21$ & - \\
\hline $\mathrm{RP}(6-10 \mathrm{~cm})$ & & $\mathrm{Y}=\mathrm{Ym}=5,86$ & - \\
\hline $\mathrm{RP}(11-15 \mathrm{~cm})$ & & $\mathrm{Y}=\mathrm{Ym}=9,33$ & - \\
\hline $\mathrm{RP}(16-20 \mathrm{~cm})$ & & $\mathrm{Y}=\mathrm{Ym}=10,04$ & - \\
\hline $\mathrm{RP}(21-25 \mathrm{~cm})$ & & $\mathrm{Y}=\mathrm{Ym}=10,31$ & - \\
\hline $\mathrm{RP}(26-30 \mathrm{~cm})$ & & $\mathrm{Y}=\mathrm{Ym}=11,18$ & - \\
\hline $\mathrm{RP}(31-35 \mathrm{~cm})$ & & $\mathrm{Y}=\mathrm{Ym}=12,08$ & - \\
\hline $\mathrm{RP}(36-40 \mathrm{~cm})$ & & $\mathrm{Y}=\mathrm{Ym}=12,81$ & - \\
\hline
\end{tabular}

DS - Densidade aparente; Dp = densidade de partículas; PT = Porosidade Total; GD = Grau de Dispersão; GF = Grau de floculação; IEAS = Índice de estabilidade de agregados a seco; IEAU = Índice de estabilidade de agregado a úmido; DMPS = Diâmetro médio ponderado a seco; DMPU = Diâmetro médio ponderado a úmido; DMGS = Diâmetro médio geométrico a seco; DMGU = Diâmetro médio geométrico a úmido; RP = Resistência à penetração no solo. ${ }^{\circ}, *$, **, *** Significativos a $10 ; 5 ; 1$ e $0,1 \%$ de probabilidade, respectivamente, pelos teste t. 
âmetro médio geométrico foi superior, na camada de 0,0 0,1 m, a partir da dose de 47,5 $\mathrm{t} \mathrm{ha}^{-1}$, de lodo de esgoto, sendo inferior ao obtido na dose de $50,0 \mathrm{t} \mathrm{ha}^{-1}$. Na dose de 25,0 t ha ${ }^{-1}$, não houve diferença significativa, comparando-se com a testemunha. Segundo os autores, a redução do diâmetro médio geométrico, na maior dose aplicada (50 $\mathrm{t} \mathrm{ha}^{-1}$ ), com relação a doses menores, deveu-se, possivelmente, à distribuição irregular das doses de lodo de esgoto durante os cinco anos do experimento.

Maria et al. (2007) obtiveram incrementos lineares do diâmetro médio ponderado dos agregados, com aumento da dose de lodo de esgoto na camada mais superficial do solo $(0-10 \mathrm{~cm})$, após dois anos consecutivos de aplicação desse resíduo. Esse comportamento não foi observado na camada de 10 a $20 \mathrm{~cm}$ de profundidade. $\mathrm{O}$ aumento do diâmetro médio ponderado na camada mais superficial deve-se ao fato de o lodo de esgoto ter sido incorporado nessa profundidade.

A aplicação de até 18,5 t ha $^{-1}$ de lodo de esgoto não alterou significativamente a resistência do solo à penetração, nas diferentes camadas do solo (Tabela 5). Esse resultado assemelha-se ao obtido por Souza et al. (2005) e Camilotti et al. (2006), que também, não observaram alterações na resistência do solo à penetração pela aplicação de lodo de esgoto. Entretanto, menor resistência do solo à penetração na camada superficial de um Latossolo Vermelho, que recebeu $24 \mathrm{t} \mathrm{ha}^{-1}$ desse resíduo, foi verificada por Barbosa et al. (2002).

\section{CONCLUSÕES}

A adição de silicato de cálcio e magnésio, em solo irrigado com água alcalina, não influencia os atributos físicos do solo.

A aplicação de lodo de esgoto ao solo diminui o grau de dispersão de argilas e aumenta a porosidade total do solo, o grau de floculação de argilas e o índice de estabilidade de agregados a úmido.

Não há influência do lodo de esgoto na densidade aparente do solo, na densidade de partículas, no índice de estabilidade de agregados a seco, no diâmetro médio ponderado seco, no diâmetro médio ponderado úmido, no diâmetro médio geométrico a seco, no diâmetro médio geométrico a úmido e na resistência à penetração do solo.

\section{REFERÊNCIAS}

Aggelides SM \& Londra PA (2000) Effects of compost produced from town wastes and sewage sludge on the physical properties of a loamy and clay soil. Bioresource Technology, 71:253-259.

Alleoni LRF, Mello JWV \& Rocha WSD (2009) Eletroquímica, adsorção e troca iônica no solo. In: Mello VF \& Alleoni LRF (Eds.) Química e mineralogia do solo - Parte II: Aplicações. Viçosa. Sociedade Brasileira de Ciência do Solo, p. 69-130.
Andrade CA, Oliveira C \& Cerri CC (2005) Qualidade da matéria orgânica e estoques de carbono e nitrogênio em latossolo tratado com biossólido e cultivado com eucalipto. Revista Brasileira de Ciência do Solo, 29:803-816.

Barbosa GMC, Tavares Filho J \& Fonseca ICB (2002) Avaliações de propriedades físicas de um Latossolo Vermelho eutroférrico tratado com lodo de esgoto por dois anos consecutivos. Sanare, 17:94-101.

Bayer C \& Mielniczuk J (2008) Dinâmica e função da matéria orgânica. In: Santos GA, Silva LS, Canellas LP \& Camargo FAO (eds.) Fundamentos da matéria orgânica do solo. Porto Alegre, Metrópole. p. 7-18.

Camilotti F, Andrioli I, Marques MO, Silva AR, Tasso Júnior LC \& Nobile FO (2006) Atributos físicos de um latossolo cultivado com cana-de-açúcar após aplicações de lodo de esgoto e vinhaça. Engenharia Agrícola, 26:738-747.

CFSEMG - Comissão de fertilidade de solo do estado de Minas Gerais (1999) Recomendação para o uso de corretivos e fertilizantes em Minas Gerais: $5^{\mathrm{a}}$ Aproximação. Viçosa, Comissão de Fertilidade do Solo do Estado de Minas Gerais, 359p.

Corrêa JC, Bull LT, Crusciol CAC \& Moraes MH (2009) Alteração de atributos físicos em latossolo com aplicação superficial de escória de aciaria, lama cal, lodos de esgoto e calcário. Revista Brasileira de Ciência do Solo, 33:263-272.

Debosz K, Petersen SO, Kure LK \& Ambus P (2002) Evaluating effects of sewage sludge and household compost on soil physical, chemical and microbiological properties. Applied Soil Ecology, 19:237-248.

Dufranc G, Dechen SCF, Freitas SS \& Camargo AO (2004) Atributos físicos, químicos e biológicos relacionados com a estabilidade de agregados de dois latossolos em plantio direto no estado de São Paulo. Revista Brasileira de Ciência do Solo, 28:505-517.

Dynia JF, Souza MD \& Boeira RC (2006) Lixiviação de nitrato em Latossolo cultivado com milho após aplicações sucessivas de lodo de esgoto. Pesquisa Agropecuária Brasileira, 41:855-862.

EMBRAPA (1997) Manual de métodos de análise de solo. 2a ed. Rio de Janeiro, 212 p.

Epstein E (1999) Silicon. Anual Review of Plant Physiology and plant Molecular Biology, 50:641-664.

Ernani PR (2008) Química do solo e disponibilidade de nutrientes. Lages: O Autor, 230 p.

Faria RJ (2000) Efeito da acumulação de silício e a tolerância das plantas de arroz de sequeiro ao déficit hídrico do solo. Dissertação de mestrado. Universidade Federal de Lavras, Lavras, 98 p.

García-Orenes F, Guerrero C, Mataix-Solera J, Navarro-Pedreno J, Gomez I \& Mataix-Beneyto J (2005) Factors controlling the aggregate stability and bulk density in two different degraded soils amended with biosolids. Soil \& Tillage Research, 82:65-76.

Jorge JA, Camargo OA \& Valadares JMAS (1991) Condições físicas de um Latossolo Vermelho-Escuro quatro anos após aplicação de lodo de esgoto e calcário. Revista Brasileira de Ciência do Solo, 15:237-240.

Korndörfer GH, Pereira HS \& Camargo MS (2002) Silicatos de cálcio e magnésio na agricultura. Uberlândia, UFU/ICAG. 23p.

Marciano CR, Moraes SO, Oliveira FC \& Mattiazzo ME (2001) Efeito do lodo de esgoto e do composto de lixo urbano sobre a condutividade hidráulica de um Latossolo Amarelo saturado e não saturado. Revista Brasileira de Ciência do Solo, 25:1-9.

Maria IC, Chiba MK, Costa A, Berton RS (2010) Sewage sludge application to agricultural land as soil physical conditioner. Revista Brasileira de Ciência do Solo, 34:967-974. 
Maria IC, Kocssi MA \& Dechen SCF (2007) Agregação do solo em área que recebeu lodo de esgoto. Bragantia, 66:291-298.

Melo VP (2002) Propriedades químicas e disponibilidade de metais pesados para a cultura do milho em dois latossolos que receberam a adição de biossólido. Dissertação de mestrado. Universidade Estadual Paulista, Jaboticabal, 134p.

Melo VP, Beutler NA, Souza ZM, Centurion JF \& Melo WJ (2004) Atributos físicos de Latossolos adubados durante cinco anos com biossólido. Pesquisa Agropecuária Brasileira, 39:67-72.

Portugal AF, Costa ODV, Costa LM da \& Santos BCM dos (2008) Atributos químicos e físicos de um Cambissolo Háplico Tb distrófico sob diferentes usos na zona da mata mineira. Revista Brasileira de Ciência do Solo, 32:249-258.

Silva IR \& Mendonça ES (2007) Matéria orgânica do solo. In Novais RF, Alvarez VH, Barros NF, Fontes RLF, Cantarutti RB \& Neves JCL (Eds.) Fertilidade do solo. Viçosa. SBCS, p.275-356.
Souza ZM, Beutler NA, Melo VP \& Melo WJ (2005) Estabilidade de agregados e resistência à penetração em Latossolos adubados por cinco anos com biossólido. Revista Brasileira de Ciência do Solo, 29:117-123.

Tavares Filho J, Barbosa GMC, \& Ribon AA (2010) Waterdispersible clay in soils treated with sewage sludge. Revista Brasileira de Ciência do Solo, 34:1527-1534.

Trannin ICB, Siqueira JO \& Moreira FMS (2008) Atributos químicos e físicos de um solo tratado com biossólido industrial e cultivado com milho. Revista Brasileira de Engenharia Agrícola e Ambiental, 12:223-230. 